\title{
Psychometric Properties of the German Version of the Children's Rejection Sensitivity Questionnaire (CRSQ)
}

\author{
Charlotte Rosenbach* \\ Department of Clinical Psychology and Psychotherapy, Freie Universität Berlin, Berlin, Germany \\ Babette Renneberg \\ Department of Clinical Psychology and Psychotherapy, Freie Universität Berlin, Berlin, Germany \\ Herbert Scheithauer \\ Department of Education and Psychology, Freie Universität Berlin, Berlin, Germany
}

\begin{abstract}
Rejection Sensitivity (RS) is defined as the disposition to anxiously expect, readily perceive, and overreact to social rejection cues. Aim of the two studies presented in this paper was to develop and administer an instrument to assess RS in a German sample of healthy (pre)adolescents as well as in a clinical sample. The English Children's Rejection Sensitivity Questionnaire (CRSQ) was translated, adapted, and presented to a non-clinical sample $(\mathrm{N}=128)$ (Study I) to identify psychometric properties of the instrument. In Study II, the resulting questionnaire was completed by a mixed clinical sample $(\mathrm{N}=50)$. Differences in results between samples, and the relation between rejection sensitivity and mental distress were investigated. The resulting German version of the questionnaire CRSQ (German: Fragebogen zur Zurückweisungsempfindlichkeit für Kinder und Jugendliche, FZE-K) showed good psychometric properties. Differences between samples provide insight into the diversity of the construct "rejection sensitivity".
\end{abstract}

\section{Keywords}

Children's Rejection Sensitivity Questionnaire (CRSQ), psychometric properties, clinical and non-clinical sample, German translation, Fragebogen zur Zurückweisungsempfindlichkeit für Kinder und Jugendliche (FZE-K)

Experiences of social rejection are common events in every person's life. Every child or adult can report situations in which she or he was rejected by others. One factor that influences the perception of and reaction to social rejection is the individual degree of rejection sensitivity (Downey \& Feldman, 1996). Rejection sensitivity is defined as the disposition to anxiously expect, readily perceive, and overreact to social rejection (Downey

\footnotetext{
*Address for correspondence

Charlotte Rosenbach, Freie Universität Berlin, Department of Education and Psychology, Clinical Psychology and Psychotherapy, Habelschwerdter Allee 45, D-14195 Berlin. E-mail: c.rosenbach@fu-berlin.de
}

\& Feldman, 1996). Individuals with high levels of rejection sensitivity assume to rather be excluded than included in interpersonal relationships, the behavior of others is quickly (and sometimes unjustifiably) perceived and interpreted as rejection, and the reaction to perceived rejection is disproportionally intense.

In their model of rejection sensitivity, Downey and Feldman (1996) state that individuals experiencing repeated and continuous rejection in early childhood (e.g., dismissive parenting, exclusion by peers) develop a disposition of expecting recurring exclusion and rejection. As a result, they show a high vigilance towards and a quick perception of potential 
rejection cues even in neutral situations. Subsequent reactions in form of social withdrawal or aggressive behavior in turn can lead to actual rejection by others - in terms of a self-fulfilling prophecy. So far, only few studies have investigated the role of early social experiences for rejection sensitivity in a longitudinal design. Godleski and colleagues (2019) found family conflicts and maternal harshness in early childhood to be associated with later rejection sensitivity in adolescents. Araiza, Freitas, and Klein (2020) could not confirm the relevance of early social experiences with parents or peers for later rejection sensitivity. Nevertheless, they showed temperamental negative affect at age 6 and 9 to predict rejection sensitivity at age 12.

In adults as well as in children, rejection sensitivity can add to the development and maintenance of emotional and behavioral problems (for an overview see Gao, Assink, Cipriani, \& Lin, 2017; Gao, Assink, Liu, Chan, \& Ip, 2021; Rosenbach \& Renneberg, 2011). In various samples of children and adolescents, rejection sensitivity was associated with symptoms of depression (Bondü, Sahyazici-Knaak, \& Esser, 2017; Cassidy \& Stevenson, 2005; Chango, McElhaney, Allen, Schad, \& Marston, 2012; Harper, Dickson, \& Welsh, 2006; Zhou, Li, Tian, \& Huebner, 2020), aggressive behavior (Cassidy \& Stevenson, 2005; Downey, Lebolt, Rincón, \& Freitas, 1998), anxiety (London, Downey, Bonica, \& Paltin, 2007; McCarty, Vander Stoep, \& McCauley, 2007; McDonald, Bowker, Rubin, Laursen, \& Duchene, 2010; Zimmer-Gembeck et al., 2021), ADHD (Babinski, Kujawa, Kessel, Arfer, \& Klein, 2019), and PostTraumatic Stress Disorder (Wang \& Chung, 2020).

Main aim of the present studies was to provide a German instrument to assess rejection sensitivity in children and adolescents. Therefore, the original English version of the Children's Rejection Sensitivity Questionnaire (CRSQ; Downey et al., 1998) was translated and slightly adapted to the German cultural context (e.g., types of school). In a sample of 128 (pre)adolescents, the translated version was tested for its psychometric properties (Study I). In a second step, the questionnaire was verified in a clinical sample (Study II).

\section{The Children Rejection Sensitivity Questionnaire}

The original version of the CRSQ (Downey et al., 1998) has two parts. The first part consists of 12 ambiguous social situations (before a social rejection might occur) that are rated on three subscales: a) how nervous the person would be (anxiety), b) how mad the person would be (anger), and c) to what extent the person would expect to be rejected by the other person (expectancy). Two scores can be computed: anxious rejection sensitivity (for each item the anxiety-score is multiplied with the expectancy-score, summed up for all 12 items and then divided by 12), and angry rejection sensitivity (same calculation as anxious expectation but with the angry-scores). The authors postulate two independent factors of anxious and angry rejection sensitivity, respectively. Nevertheless, several studies used only parts of the CRSQ (e.g., only angry rejection sensitivity: Cassidy \& Stevenson, 2005; only anxious rejection sensitivity: Zimmer-Gembeck, Trevaskis, Nesdale, \& Downey, 2014; one general score of all 36 items: Sandström, Cillessen, \& Eisenhower, 2003) or could not confirm the two-factor solution (Duzman, 2005; London et al., 2007; Purdie \& Downey, 2000). Other authors point to the better prediction of aggressive behavior through angry rejection sensitivity (Bondü \& Krahé, 2015; Jacobs \& Harper, 2013), or showed anxious rejection sensitivity but not angry rejection sensitivity to be relevant for the association between school relations and loneliness (Molinari, Grazia, \& Corsano, 2020).

Previous to the present studies, the English version of the questionnaire was translated and backtranslated by different experts and native speakers and then presented to a sample of 114 adolescents (mean age $M=15$ ). A factor analysis over all anxious and angry items did not show two independent factors but rather all items loaded on one factor. Therefore, a two-factor solution with the assumption that two different and independent forms of rejection sensitivity were measured could not be sustained. Due to the better psychometric properties of the anxious items, we created a German version of the first part of the CRSQ with nine social situations for which anxiety and expectancy are rated. Additionally, this solution with two scales assessing anxious expectation of rejection conforms to the German adult version of the RSQ (see Staebler, Hellbing, Rosenbach, \& Renneberg, 2010).

The second part of the original version of the CRSQ was conceptualized to assess reactions and intentions after an actual interpersonal rejection experience. Therefore, a hypothetical rejection experience by peers was presented and the individual probability of 16 emotional and behavioral reactions was rated. To our knowledge, there are no available data regarding 
the psychometric properties of this second part. In the pilot study, this second part was also translated and back-translated by a native speaker's expert team. No clear or interpretable factor structure of the translated second part of the CRSQ was detected. Therefore, a selected team of experts, including the authors, conceptualized a new version taking into account the findings regarding clinical correlations of rejection sensitivity (depressive symptoms, anxiety, and aggression). The second part of the German version of the CRSQ then consisted of 17 new items, assessing angry and aggressive reactions, sadness, and desperation, as well as resignation, and self-devaluation.

\section{The Present Studies}

In the following, two studies are presented. In the first study, the German CRSQ (German: Fragebogen zur Zurückweisungsempfindlichkeit für Kinder und Jugendliche, FZE-K, Rosenbach \& Renneberg, 2012) was presented to a sample of 128 (pre)adolescents. Main aim was to investigate the psychometric properties of the translated version using a non-clinical sample. The second study was designed to test the questionnaire in a mixed clinical sample. Additionally, mental distress was assessed in both studies.

\section{Study I}

\section{Method}

\section{Participants}

Data were collected within the context of the evaluation of a bullying prevention program (Fairplayer. Manual; Scheithauer, Walcher, Warncke, Klapprott, \& Bull, 2019; cf. Bull, Schultze, \& Scheithauer, 2009). The sample consisted of 128 (pre)adolescent students (50\% female) from a German high school (age $M=13.06, S D=0.80$; range $11-15$ years). Participants completed the questionnaires during class, under guidance of a project assistant. All participants were informed about the aims of the study. All parents of participants gave their written consent (for participation and publication of data). The authors assert that all procedures contributing to this work comply with the ethical standards of the relevant national and institutional committees on human experimentation and with the Helsinki Declaration of 1975, as revised in 2008.

\section{Measures}

Rejection Sensitivity. The German version of the CRSQ (Fragebogen zur Zurückweisungsempfindlichkeit für Kinder und Jugendliche, FZE-K, Rosenbach \& Renneberg, 2012) consists of two parts: The first part assesses the anxious expectation of rejection via nine situations in which the (pre)adolescent either awaits to be accepted or rejected before an actual rejection happens (e.g., "Imagine you're in your classroom, and everyone is splitting up into six groups to work on a project. You sit there and watch lots of other kids getting picked. As you wait, you wonder if the kids want you for their group."). Participants are asked to rate their anxiety ("how nervous would you be ...") and the expectancy to be included / rejected ("Do you think you will get picked?"), both on a 6-point Likert scale. The overall score for rejection sensitivity is calculated by multiplying scores for each situation (anxiety*expectancy), summarizing the scores for all nine situations and building the mean (range 1-36, 1 indicating a very low degree of rejection sensitivity and 36 a high degree of rejection sensitivity). Additionally, both the anxiety as well as the expectancy subscales are analyzed separately through their mean scores (range 1-6 with higher values indicating higher anxiety or expectancy). Part two consists of 17 items and assesses emotional and behavior reaction intentions after a hypothetical rejection has occurred ("Imagine the following situation: All of your friends were invited for a birthday party. You didn't get an invitation. How would you feel, what would you think?"). Participants rate their anticipated reactions (e.g., "I would think that the other person doesn't care about me") on a 5point Likert scale $(1=$ not true at all; $5=$ very true $)$. The three identified factors (see result section) are interpreted via their mean scores.

Psychopathology. The Symptom Checklist (SCLK-9; Klaghofer \& Brähler, 2001) assesses with nine items the perceived mental distress during the past seven days. Items were slightly modified to address (pre)adolescents appropriately. The internal consistency of $\alpha=0.88$ in the present study was the same as in the original study (Klaghöfer \& Brähler, 2001).

\section{Results}

Descriptive results and psychometric properties of the FZE-K are shown in Table 1. The mean score of the first part of the FZE-K for rejection sensitivity 
Table 1

Psychometric Properties of the FZE-K in a Non-Clinical Sample (Study I)

\begin{tabular}{|c|c|c|c|c|c|c|c|}
\hline FZE-K scales & $\begin{array}{c}M(S D) \text { Total } \\
\text { sample }\end{array}$ & $\begin{array}{l}M(S D) \\
\text { Female }\end{array}$ & $\begin{array}{c}M(S D) \\
\text { Male }\end{array}$ & $\begin{array}{c}\text { Cronbach's } \\
\text { alpha }(\alpha)\end{array}$ & $\begin{array}{c}\text { Skewness } \\
\quad(S E)\end{array}$ & $\begin{array}{l}\text { Curtosis } \\
\quad(S E)\end{array}$ & $\begin{array}{c}\text { Item inter- } \\
\text { correlation }\left(r_{\mathrm{it}}\right)\end{array}$ \\
\hline Part I Rejection sensitivity & $8.59(3.86)$ & $8.93(3.73)$ & $8.35(4.01)$ & 0.82 & $0.42(0.21)$ & $-0.20(0.43)$ & $0.52-0.74$ \\
\hline Part I Anxiety & $2.87(0.89)$ & $3.03(0.83)^{*}$ & $2.72(0.94)^{*}$ & 0.81 & $-0.17(0.21)$ & $-0.37(0.42)$ & $0.27-0.76$ \\
\hline Part I Expectancy & $2.84(0.85)$ & $2.76(0.72)$ & $2.94(0.97)$ & 0.81 & $0.61(0.21)$ & $1.56(0.42)$ & $0.51-0.81$ \\
\hline Part II Disappointment, grief & $2.57(0.97)$ & $2.86(0.98)^{* *}$ & $2.31(0.89)^{* *}$ & 0.76 & $0.23(0.21)$ & $-0.74(0.42)$ & $0.69-0.84$ \\
\hline Part II Anger, aggression & $2.18(0.89)$ & $2.18(0.91)$ & $2.22(0.87)$ & 0.80 & $0.75(0.21)$ & $0.06(0.42)$ & $0.58-0.83$ \\
\hline Part II Resignation, self-attribution & $2.04(0.75)$ & $2.06(0.74)$ & $2.05(0.76)$ & 0.80 & $0.76(0.21)$ & $0.04(0.42)$ & $0.59-0.77$ \\
\hline
\end{tabular}

*Significant gender differences $(d f=128)\left({ }^{*} p<0.05,{ }^{* *} p<0.01\right)$.

Table 2

Factor Loadings of Items of the FZE-K, Part II (Study I)

\begin{tabular}{|c|c|c|c|c|}
\hline \multirow[t]{2}{*}{ Item- nr. } & & \multicolumn{3}{|c|}{ Factor/Scale } \\
\hline & & $\begin{array}{l}\text { Resignation and } \\
\text { self-attribution }\end{array}$ & $\begin{array}{l}\text { Anger and } \\
\text { aggression }\end{array}$ & $\begin{array}{l}\text { Disappointment } \\
\text { and grief }\end{array}$ \\
\hline 1 & I don't matter to person & & & 0.644 \\
\hline 3 & I mull over person & & & 0.728 \\
\hline 10 & Feeling sad & & & 0.762 \\
\hline 13 & Feeling disappointed & & & 0.741 \\
\hline 2 & I will never be invited again & 0.675 & & \\
\hline 4 & My own fault & 0.811 & & \\
\hline 5 & Person did this on purpose & 0.666 & & \\
\hline 7 & It is something I did wrong & 0.683 & & \\
\hline 12 & Feeling helpless & 0.524 & & \\
\hline 16 & No one cares & 0.646 & & \\
\hline 17 & I don't like the person no more & 0.443 & & \\
\hline 6 & Like to hit person & & 0.714 & \\
\hline 8 & Avoid person & & 0.476 & \\
\hline 9 & Payback & & 0.817 & \\
\hline 11 & Person will see what happens & & 0.780 & \\
\hline 14 & Angry & & 0.648 & \\
\hline 15 & Destroy something & & 0.542 & \\
\hline
\end{tabular}

$(M=8.59, S D=3.86)$ is comparable to the mean score of the original version $(M=8.16, S D=3.91$; Downey et al., 1998). Gender differences can be reported only for anxiety with girls $(M=3.03, S D=0.83)$ scoring significantly higher than boys $(M=2.72, S D=0.94 ; t$ $[126]=1.00, p=0.049)$. All scales are normally distributed $(D[122]=0.05-0.07$, n.s.).

All items of the second part of the KZE-K were newly conceptualized, thus they were analyzed using exploratory factor analysis. Kaiser-MeyerOlkin measure of sampling adequacy was 0.80, above the commonly recommended value of 0.6 , and Bartlett's test of sphericity was significant $(\chi 2$ $(136)=768.52, p<0.001)$. The diagonals of the antiimage correlation matrix were also all over 0.5 . Finally, the communalities were all above 0.3, further confirming that each item shared some common variance with other items. Given these overall indicators, factor analysis was deemed to be suitable with all 17 items. Principal components analysis with varimax rotation was used. Best solution was offered by three factors with $53 \%$ of variance explained (see Table 2). Related to content and theoretical support, the three factors can be classified as follows: anger and aggression, disappointment and grief, and resignation and self-attribution. None of the scales is normally distributed $(D[127]=0.09-0.13, p<0.05)$, all internal consistencies are satisfying (Table 1). Boys and girls differ only in disappointment and grief with girls showing higher scores than boys ( $t$ $[126]=3.27, p<0.01)$.

Correlations between the scales of the first and the second part of the FZE-K are shown in Table 3. Disappointment and grief, and resignation and selfattribution are significantly correlated with rejection sensitivity and anxiety (all $p<0.01)$. Resignation and self-attribution is additionally associated with expectancy $(p<0.05)$. Anger and aggression does not show any association with the scales of part I.

The relation between rejection sensitivity and mental distress was analyzed via correlations (Table 4). Mental distress (SCL-K-9) was associated with 
Table 3

Intercorrelation ( $r$ ) Between FZE-K Scales (Study I) in the Non-Clinical Sample

\begin{tabular}{lccc}
\hline & $\begin{array}{c}\text { Part II } \\
\text { Disappointment, } \\
\text { grief }\end{array}$ & $\begin{array}{c}\text { Part II } \\
\text { Anger, } \\
\text { aggression }\end{array}$ & $\begin{array}{c}\text { Part II } \\
\text { Resignation, } \\
\text { self-attribution }\end{array}$ \\
\hline Part I Rejection sensitivity & $\mathbf{0 . 2 9}^{* *}$ & 0.05 & $\mathbf{0 . 3 0}^{* *}$ \\
Part I Anxiety & $\mathbf{0 . 4 1}^{* *}$ & 0.11 & $\mathbf{0 . 2 6}^{* *}$ \\
Part I Expectancy & -0.04 & -0.08 & $\mathbf{0 . 1 8}^{*}$ \\
${ }^{*} p<0.05$ (2-sided). ${ }^{* *} p<0.01$ (2-sided). & & &
\end{tabular}

Table 4

Correlations ( $r)$ FZE-K and SCL (Study I + II)

\begin{tabular}{|c|c|c|c|c|c|c|c|}
\hline & & \multicolumn{6}{|c|}{ FZE-K } \\
\hline & & $\begin{array}{l}\text { Rejection } \\
\text { sensitivity }\end{array}$ & Anxiety & Expectancy & $\begin{array}{l}\text { Disappointment, } \\
\text { grief }\end{array}$ & $\begin{array}{c}\text { Anger, } \\
\text { aggression }\end{array}$ & $\begin{array}{l}\text { Resignation, } \\
\text { self-attribution }\end{array}$ \\
\hline Study I & SCL-K-9 & $\mathbf{0 . 2 8}^{* *}$ & $\mathbf{0 . 3 1} 1^{* *}$ & 0.12 & 0.18 & $0.32^{* *}$ & 0.20 \\
\hline Study II & & $0.57^{* *}$ & $0.47^{* *}$ & $0.566^{* *}$ & $0.47^{* *}$ & 0.17 & $0.64^{* *}$ \\
\hline
\end{tabular}

** $p<0.001$ (2-sided).

rejection sensitivity $(r=0.28, p<0.001)$, anxiety $(r=0.31, p<0.001)$, and anger and aggression $(r=0.32, p<0.001)$.

\section{Discussion}

Overall, the psychometric properties of the FZE$\mathrm{K}$ are satisfactory. The FZE-K allows to calculate three different scores: overall rejection sensitivity, anxiety of social rejection, and perceived expectancy to be rejected. Additionally, the second part of the questionnaire assesses anticipated emotional and behavioral reactions after experiencing interpersonal rejection. These reactions are coded as anger and aggression, disappointment and grief, and resignation and self-attribution.

Results for the first part of the FZE-K indicate that the two subscales assess different aspects. Only anxiety is associated with mental distress, whereas expectancy is not. This might indicate that anxiety assesses situational negative emotions and expectancy rather then a stable basic assumption to be accepted or rejected, that is less related to the actual mental state. The three identified scales of the second part of the FZE-K are in accordance with previous assumptions about potential reactions to social rejection (Rosenbach \& Renneberg, 2011), i.e., showing aggressive, depressive, and social-anxious behavior patterns.

Taken together, the German version of the FZE-K turns out to be a suitable instrument to assess rejection sensitivity in (pre)adolescents. Results indicate that high levels of rejection sensitivity are associated with higher levels of mental distress (SCL-K-9).

\section{Study II}

Method

\section{Participants}

Data of the clinical sample $(\mathrm{N}=50)$ were collected at the Vivantes Department of Child and Adolescent Psychiatry, Psychotherapy and Psychosomatics in Berlin, Germany. Participants were aged between 10 and 17 years $(M=14.32, S D=2.15 ; 44 \%$ female $)$ and were all in inpatient treatment. Questionnaires were administered in the presence of a research assistant, who could be addressed in case of ambiguity. It should be noted that difficulties in understanding the questions led to a high number of missing values in younger participants (aged 8 and 9) of the initial sample, so that these were excluded from analyses $(n=5)$. All participants were informed about the aims of the study. All parents of participants gave their written consent for data collection and publication of data. The authors assert that all procedures contributing to this work comply with the ethical standards of the relevant national and institutional committees on human experimentation and with the Helsinki Declaration of 1975, as revised in 2008 .

\section{Measures}

The FZE-K and the SCL-K-9 (both as in study I; see above) were applied. Clinical diagnoses were 
Table 5

Psychometric Properties of the FZE-K in a Clinical Sample (Study II)

\begin{tabular}{lccccccc}
\hline FZE-K scales & $\begin{array}{c}M(S D) \text { Total } \\
\text { sample }\end{array}$ & $\begin{array}{c}M(S D) \\
\text { Female }\end{array}$ & $\begin{array}{c}M(S D) \\
\text { Male }\end{array}$ & $\begin{array}{c}\text { Cronbach's } \\
\text { alpha }(\alpha)\end{array}$ & $\begin{array}{c}\text { Skewness } \\
(S E)\end{array}$ & $\begin{array}{c}\text { Curtosis } \\
(S E)\end{array}$ & $\begin{array}{c}\text { Item inter- } \\
\text { correlation }\left(r_{\text {it }}\right)\end{array}$ \\
\hline Part I Rejection sensitivity & $\mathbf{1 1 . 6 8}^{*} \mathbf{( 5 . 8 7 )}$ & $12.47(6.39)$ & $11.06(5.47)$ & 0.86 & $0.58(0.34)$ & $-0.28(0.66)$ & $0.42-0.80$ \\
Part I Anxiety & $\mathbf{3 . 3 9}^{*}(\mathbf{0 . 9 5})$ & $3.47(1.04)$ & $3.33(0.89)$ & 0.75 & $-0.16(0.34)$ & $-0.48(0.66)$ & $0.49-0.78$ \\
Part I Expectancy & $3.13(1.05)$ & $3.31(1.09)$ & $2.99(1.01)$ & 0.83 & $0.08(0.34)$ & $-0.71(0.66)$ & $0.39-0.77$ \\
Part II Disappointment, grief & $\mathbf{3 . 3 6}^{*}(\mathbf{1 . 0 1})$ & $3.48(1.02)$ & $3.26(1.02)$ & 0.72 & $-0.14(0.33)$ & $-0.62(0.66)$ & $0.59-0.85$ \\
Part II Anger, aggression & $2.16(0.96)$ & $2.14(0.94)$ & $2.17(0.98)$ & 0.79 & $0.99(0.34)$ & $0.66(0.66)$ & $0.57-0.89$ \\
Part II Resignation, self-attribution & $\mathbf{2 . 4 5 *}^{*}(\mathbf{0 . 8 5})$ & $2.61(0.91)$ & $2.33(0.79)$ & 0.80 & $0.22(34)$ & $-0.79(0.66)$ & $0.47-0.81$ \\
\hline
\end{tabular}

*Differs significantly from non-clinical sample of study I $(p<0.01)$.

Table 6

Intercorrelation (r) Between FZE-K Scales (Study II) in the Clinical Sample

\begin{tabular}{lccc}
\hline & $\begin{array}{c}\text { Part II } \\
\text { Disappointment, } \\
\text { grief }\end{array}$ & $\begin{array}{c}\text { Part II } \\
\text { Anger, } \\
\text { aggression }\end{array}$ & $\begin{array}{c}\text { Part II } \\
\text { Resignation, } \\
\text { self-attribution }\end{array}$ \\
\hline Part I Rejection sensitivity & $\mathbf{0 . 5 0}^{* *}$ & 0.15 & $\mathbf{0 . 6 0}^{* *}$ \\
Part I Anxiety & $\mathbf{0 . 5 7}^{* *}$ & 0.18 & $\mathbf{0 . 5 4}^{* *}$ \\
Part I Expectancy & $0.35^{*}$ & 0.24 & $\mathbf{0 . 4 9}^{* *}$ \\
\hline
\end{tabular}

${ }^{*} p<0.05$ (2-sided) ${ }^{* *} p<0.01$ (2-sided).

assessed by trained clinical psychologists during the standard diagnostic process.

\section{Results}

Descriptives of the FZE-K are shown in Table 5. No gender differences were found. The mean score of rejection sensitivity (first part of the FZEK) $(M=11.68, S D=5.87)$ was significantly higher than rejection sensitivity in the non-clinical sample from study I $(t[178]=4.13, p<0.001)$. The same applies for anxiety $(M=3.39, \mathrm{SD}=0.95 ; t[178]=$ $3.48, p<0.001)$, but not for expectancy $(t[178]=$ $1.96, p=0.52)$. Compared to the non-clinical data (study I), the clinical sample reports higher levels of disappointment and grief $(M=3.36, S D=1.01$; $t[177]=4.78, p<0.01)$ and resignation and selfattribution $(M=2.45, S D=0.85 ; t \quad t[177]=3.20$, $p<0.01$ ). All (sub)scales show satisfying psychometric properties (Table 5). Similar as in study I, the scales of the first part of the FZE-K are correlated with disappointment and grief, and resignation and self-attribution, but not with anger and aggression (Table 6).

All FZE-K scales except anger and aggression, were positively associated with the SCL-K-9 (Table 4).

Two subsamples (internalizing and externalizing disorders) were differentiated based on the main diagnosis as given by the treating clinical

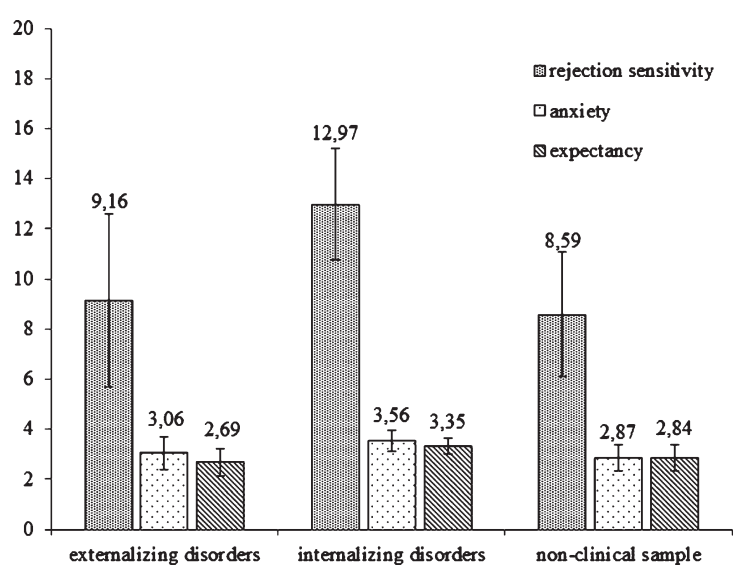

Fig. 1. Differences between clinical subsamples in rejection sensitivity scales.

psychotherapist. Internalizing disorders include mainly affective and anxiety disorders (total $n=33$ ), externalizing disorders comprise mainly conduct disorders and ADHD (total $n=17$ ). Mean scores are shown in Fig. 1. Participants with internalizing disorders reported higher levels of rejection sensitivity $(U=2.18, p=0.029)$ as well as higher levels of anxiety $(U=2.03, p=0.0 .49)$, but did not differ from those with externalizing disorders on the expectancy scale $(U=1.90, p=0.058)$. The difference in rejection sensitivity is therefore due to the difference in anxiety. No differences between groups were found in the second part of the FZE-K. 


\section{Discussion}

Results of this second study confirm the previously reported satisfying psychometric properties of the German version (FZE-K) of the CRSQ. Data demonstrate that children and adolescents in inpatient treatment report significantly higher levels of rejection sensitivity than a healthy sample of children. This difference is due to their higher anxiety score and less to their expectancy of being rejected. This implies that children with mental disorders are more anxious of being rejected but do not rate the probability higher than children and adolescents without mental disorders. By comparison, children with internalizing disorders report being more rejection sensitive than children with externalizing disorders. This difference, too, is attributable to the former's higher anxiety, but not to a higher expectancy of being rejected. In this sample, mainly affective and anxiety disorders were summarized under the internalizing disorders, that means, disorders characterized by high levels of anxiety and worry. Therefore, it seems comprehensible that this group is more anxious of being rejected. Due to the small sample size, results have to be seen as preliminary and interpreted with caution.

\section{General Discussion}

Main aim of the two studies was to test the German version of the "Children Rejection Sensitivity Questionnaire" (Downey et al., 1998; German: Fragebogen zur Zurückweisungsempfindlichkeit für Kinder und Jugendliche, FZE-K, Rosenbach \& Renneberg, 2012). The psychometric properties of the questionnaire were identified as satisfying. Additionally, the application of the FZE-K in a clinical sample was tested. Here, difficulties in understanding the questions were observed in children younger than 10 years. Therefore, it should be noted that the FZE-K is appropriate only for children and adolescents aged 10 and older.

The FZE-K assesses with the scale rejection sensitivity the anxious expectation of being rejected in a social context. Results of both studies indicate that the anxiety of and the expectation of being rejected can be evaluated separately over the two subscales anxiety and expectation, which assess different aspects of rejection sensitivity. A recent study conducted by Preti, Casini, Richetin, De Panfilis, and Fontana (2020) confirms anxiety and expectation measuring different aspects of rejection sensitivity.
Interestingly, differences between the clinical and non-clinical samples as well as between the clinical subsamples were accounted for by differences in the levels of anxiety of rejection but not by the expectation of rejection. This might indicate that the anticipated likelihood of being accepted or rejected by a social group is rather a stable basic assumption, whereas the anxiety of being rejected might vary depending on the actual mental distress. These results point to the complexity of the construct of rejection sensitivity, a disposition that probably consists of two factors, i.e. the stable expectation of being rejected or included and the more state-dependent anxiety of being socially rejected. This assumption needs further verification.

The second part of the FZE-K assesses behavioral intentions and emotional reactions after being rejected. Over three scales these reactions and intentions encompass aggressive, depressive, and anxious tendencies. Previous assumptions and a few empirical findings indicate that in children and adolescents, high levels of rejection sensitivity are associated with depressive reactions (Harper et al., 2006), social withdrawal (London et al., 2007). or aggressive behavior (Cassidy \& Stevenson, 2005). By contrast, results of the present studies show that rejection sensitivity is related to mental distress as well as to resignation, disappointment, and social withdrawal, but is not related to aggressive behavior tendencies. Also, children and adolescents with externalizing disorders report lower levels of rejection sensitivity than those with internalizing disorders. Therefore, the presented data lead to the hypothesis that high levels of rejection sensitivity (mainly high levels of anxiety of being rejected) might be of etiological and maintaining relevance for affective and anxiety disorders, but less for conduct disorders and ADHD.

Longitudinal studies are needed to examine the predictive power of rejection sensitivity in samples of children and adolescents. The significance of rejection sensitivity for the development and maintenance of mental disorders should be analyzed in larger samples. Additionally, the retest-reliability should be tested in a longitudinal design.

With the first part of the FZE-K assessing the anxious expectation of being rejected in an ambiguous situation and the second part focusing on emotional reactions and behavioral intentions after actually being rejected, the questionnaire covers the different aspects of the definition of rejection sensitivity as anxious expectation of and overreaction to social rejection cues. In light of the findings of the present 
studies, the FZE-K shows to be a suitable instrument to assess rejection sensitivity in children and adolescents. This has been shown in a study conducted by Feldmann and colleagues (2018), who applied the FZE-K in a sample of depressed adolescents and compared them to a healthy control-group. Differences between groups as well as psychometric data of the FZE-K are comparable to our data. As rejection sensitivity has been shown to function as a moderator between early aversive events and later psychopathology (e.g. Godleski et al., 2019; Rosenbach \& Renneberg, 2014), clinical child psychologists should consider to assess and address rejection sensitivity in prevention and intervention of mental disorders.

\section{References}

Araiza, A. M., Freitas, A. L., \& Klein, D. N. (2020). Socialexperience and temperamental predictors of rejection sensitivity: A prospective study. Social Psychological and Personality Science, 11, 733-742. doi:10.1177/1948550619878422

Babinski, D.E., Kujawa, A., Kessel, E.M., Arfer, K. B., \& Klein, D. N. (2019). Sensitivity to peer feedback in young adolescents with symptoms of ADHD: Examination of neurophysiological and self-report measures. Journal of Abnormal Child Psychology, 47, 605-617. doi: 10.1007/s10802-018-0470-2

Bondü, R., \& Krahé, B., (2015). Links of justice and rejection sensitivity with aggression in childhood and adolescence. Aggressive Behavior, 41, 353-368. doi: 10.1002/ab.21556.

Bondü, R., Sahyazici-Knaak, F., \& Esser, G. (2017). Long-term associations of justice sensitivity, rejection sensitivity, and depressive symptoms in children and adolescents. Frontiers in Psychology, 8, 1446. doi: 10.3389/fpsyg.2017.01446

Bull, H., Schultze, M., \& Scheithauer, H. (2009). Schoolbased prevention of bullying and relational aggression: The fairplayer.manual. International Journal of Developmental Science, 3, 312-317. doi: 10.3233/DEV-2009-3310

Cassidy, E. F., \& Stevenson, H. C., Jr. (2005). They wear the mask: Hypervulnerability and hypermasculine aggression among African American males in an urban remedial disciplinary school. Journal of Aggression, Maltreatment \& Trauma, 11, 53-74. doi: 10.1300/J146v11n04_03

Chango, J. M., McElhaney, K. B., Allen, J. P., Schad, M. M., \& Marston, E. (2012). Relational stressors and depressive symptoms in late adolescence: Rejection sensitivity as a vulnerability. Journal of Abnormal Child Psychology, 40, 369-379. doi: 10.1007/s10802-011-9570-y

Downey, G., \& Feldman, S. I. (1996). Implications of rejection sensitivity for intimate relationships. Journal of Personality and Social Psychology, 70, 1327-1343. doi: 10.1037/00223514.70.6.1327

Downey, G., Lebolt, A., Rincón, C., \& Freitas, A. L. (1998). Rejection sensitivity and children's interpersonal difficulties. Child Development, 69, 1074-1091. doi: 10.1111/j.14678624.1998.tb06161.x

Duzman, A. M. (2005). The relationships between rejection sensitivity, peer social standing, and perceived social acceptance among pre-adolescents. Dissertation Abstracts International: Section B: The Sciences and Engineering. US: ProQuest Information \& Learning.

Feldmann, L., Landes, I., Schulte-Körne, G., \& Greimel, E. (2018). Zurückweisungsempfindlichkeit bei Jugendlichen mit Depression. Zeitschrift für Kinder- und Jugendpsychiatrie und Psychotherapie, 46, 143-153. doi:10.1024/1422-4917/a000525

Gao, S., Assink, M., Cipriani, A., \& Lin, K. (2017). Associations between rejection sensitivity and mental health outcomes: A meta-analytic review. Clinical Psychology Review, 57, 59-74. doi: 10.1016/j.cpr.2017.08.007

Gao, S., Assink, M., Liu, T., Chan, K. L., \& Ip, P. (2021). Associations between rejection sensitivity, aggression, and victimization: A meta-analytic review. Trauma, Violence, and Abuse, 22, 125-135. doi: 10.1177/1524838019833005

Godleski, S. A., Eiden, R. D., Kachadourian, L., \& Lucke, J. F. (2019). Etiological pathways to rejection sensitivity in a highrisk sample. Personality and Social Psychology Bulletin, 45, 715-727. doi: 10.1177/0146167218795486

Harper, M. S., Dickson, J. W., \& Welsh, D. P. (2006). Selfsilencing and rejection sensitivity in adolescent romantic relationships. Journal of Youth and Adolescence, 35, 459-67. doi: 10.1007/s10964-006-9048-3

Jacobs, N., \& Harper, B. (2013). The effects of rejection sensitivity on reactive and proactive aggression. Aggressive Behavior, 39, 3-12. doi: 10.1002/ab.21455.

Klaghofer, R., \& Brähler, E. (2001). Konstruktion und teststatistische Prüfung einer Kurzform der SCL-90-R [Construction and test statistical evaluation of a short version of the SCL90-R]. [ Zeitschrift für Klinische Psychologie, Psychiatrie und Psychotherapie, 49, 115-124.

London, B., Downey, G., Bonica, C., \& Paltin, I. (2007). Social causes and consequences of rejection sensitivity. Journal of Research on Adolescence, 17, 481-506. doi: 10.1111/j.15327795.2007.00531.x

McCarty, C. A., Vander Stoep, A., \& McCauley, E. (2007). Cognitive features associated with depressive symptoms in adolescence: Directionality and specificity. Journal of Clinical Child and Adolescent Psychology, 36, 147-158. doi: 10.1080/15374410701274926

McDonald, K. L., Bowker, J. C., Rubin, K. H., Laursen, B., \& Duchene, M. S. (2010). Interactions between rejection sensitivity and supportive relationships in the prediction of adolescents' internalizing difficulties. Journal of Youth and Adolescence, 39, 563-574. doi: 10.1007/s10964-010-9519-4

Molinari, L., Grazia, V., \& Corsano, P. (2020). School relations and solitude in early adolescence: A mediation model involving rejection sensitivity. Journal of Early Adolescence, 40, 426448. doi: 10.1177/0272431619847523

Preti, E., Casini, E., Richetin, J., De Panfilis, C., \& Fontana, A. (2020). Cognitive and emotional components of rejection sensitivity: Independent contributions to adolescent self- and interpersonal functioning. Assessment, 27, 1230-1241. doi: $10.1177 / 1073191118817866$

Purdie, V., \& Downey, G. (2000). Rejection sensitivity and adolescent girls' vulnerability to relationship-centered difficulties. Child Maltreatment, 5, 338-349. doi: 10.1177/1077559 500005004005

Rosenbach, C., \& Renneberg, B. (2011). Abgelehnt, ausgeschlossen, ignoriert: Die Wahrnehmung sozialer Zurückweisung und psychische Störungen - eine Übersicht [Rejected, excluded, ignored: The perception of social rejection and 
mental disorders - A review]. Verhaltenstherapie, 21, 87-98. doi: $10.1159 / 000328839$

Rosenbach, C. \& Renneberg, B. (2012). Fragebogen zur Zurückweisungsempfindlichkeit bei Kindern und Jugendlichen (FZE-K) - Deutsche adaptiere Version des “Children's Rejection Sensitivity Questionnaire" (CRSQ). Berlin. Freie Universität Berlin, Arbeitsbereich Klinische Psychologie und Psychotherapie. Unveröffentliches Manuskript.

Rosenbach, C. \& Renneberg, B. (2014). Rejection sensitivity as a mediator of the relationship between experienced rejection and borderline characteristics. Personality and Individual Differences, 69, 176-181. doi: 10.1016/j.paid.2014.05.032

Sandström, M. J., Cillessen, A. H. N., \& Eisenhower, A. (2003). Children's appraisal of peer rejection experiences: Impact on social and emotional adjustment. Social Development, 12, 530550. doi: 10.1111/1467-9507.00247

Scheithauer, H., Walcher, A., Warncke, S., Klapprott, F., \& Bull, H. D. (2019). Fairplayer.Manual - Klasse 7-9: Förderung von sozialen Kompetenzen - Prävention von Mobbing und Schulgewalt. (4. Auflage) [Fairplayer.Manual - Grade 7th9th: Promotion of social competence - prevention of bullying and school violence (4th. ed.)]. Göttingen: Vandenhoeck \& Ruprecht.

Staebler, K., Hellbing, E., Rosenbach, C., \& Renneberg, B. (2010). Rejection sensitivity and Borderline Personality Disorder. Journal of Clinical Psychology and Psychotherapy, 18, 275-283. doi: 10.1002/cpp.705

Wang, Y., \& Chung, M.C. (2020). Linking rejection sensitivity, shyness and unsociability with posttraumatic stress disorder and psychiatric co-morbidity among Chinese adolescents. Psychiatric Quarterly, 91, 309-319. /doi: 10.1007/s11126019-09701-9

Zhou, J., Li, X., Tian, L., \& Huebner, E. S. (2020). Longitudinal association between low self-esteem and depression in early adolescents: The role of rejection sensitivity and loneliness. Psychology and Psychotherapy: Theory, Research and Practice, 93, 54-71. doi: 10.1111/papt.12207

Zimmer-Gembeck, M., Gardner, A., Hawes, T., Masters, M., Waters, A., \& Farrell, L. (2021). Rejection sensitivity and the development of social anxiety symptoms during adolescence: A five-year longitudinal study. International Journal of Behavioral Development, 45, 204-215. doi: 10.1177/01650 25421995921

Zimmer-Gembeck, M.J., Trevaskis, S., Nesdale, D., \& Downey, G.A. (2014). Relational victimization, loneliness and depressive symptoms: Indirect associations via self and peer reports of rejection sensitivity. Journal of Youth and Adolescence, 43, 568-582. doi: 10.1007/s10964-013-9993-6

\section{Bio Sketches}

Charlotte Rosenbach is PostDoc clinical researcher at "Clinical Psychology and Psychotherapy" at Freie Universität Berlin. Her research interests are Borderline Personality Disorder, the development and evaluation of parenting interventions, rejection sensitivity, and sexual disorders.

Babette Renneberg is Professor of Clinical Psychology and Psychotherapy at Freie Universität Berlin and head of a training center for child and adolescent psychotherapy (CBT) in Berlin (ZGFU). Her interests are basic and applied research in anxiety disorders and personality disorders.

Herbert Scheithauer is Professor of Developmental and Clinical Psychology at Freie Universität Berlin, Germany, and Head of the Unit "Developmental Science and Applied Developmental Psychology". His research interests are bullying, cyberbullying, and the development and evaluation of preventive interventions. 